\title{
The Effect of Benign Gynecologic Procedures on Ovarian Reserve: A Prospective Study
}

\author{
Jacob GP*, Mc Murphy L, Vilos GA, Power SP \\ Department of Obstetrics and Gynecology, Western University, London, Ontario, Canada
}

*Corresponding Author: Dr.George Jacob, 211 St. Clair Street, Chatham, Ontario, N7L 3J4. Canada, Email: gjacob2010@meds.uwo.ca

\begin{abstract}
The objective of this study was to determine the change in ovarian reserve (using serum antimullerian hormone levels -AMH) after ovary-sparing surgery. This was a prospective cohort study set in an academic hospital. Patients who had surgery(vaginal/laparoscopic/abdominal hysterectomy, uterine artery embolization, unilateral oophorectomy, ovarian cystectomy), in which at least one ovary was spared, were included. AMH levels were drawn pre-operatively and for a period of 3, 6, and/or 12 months postoperatively whenever possible. Among patients who had hysterectomies $(n=6)$, postoperative AMH levels overall decreased regardless of type of hysterectomy (vaginal/laparoscopic/abdominal). Patients who had ovarian surgery $(n=5)$ had a decrease in AMH, except for 2 patients who had an increase after ovarian cystectomy. Of the patients who had embolization (n=2), one had a gradual decrease in AMH, and the other had a gradual increase over 12 months. Our results showed that vaginal or laparoscopic hysterectomies did not have a protective effect on ovarian reserve compared to abdominal hysterectomies. While ovarian reserve does decrease after ovarian surgery, in some patients, AMH levels might increase after surgery presumably because of post-operative changes that allow for better follicular recruitment. Similarly, embolization might allow for improved AMH if the post-embolization uterus allows for better shunting of blood to the ovaries.
\end{abstract}

Keywords: Ovarian Reserve; Gynecologic Surgery; Hysterectomy

\section{INTRODUCTION}

Ovarian reserve refers to the size of the nongrowing or resting primordial follicle population, which determines the number of growing follicles and the quality or reproductive potential of their oocytes. It has been correlated with fecundity, time of menopause, as well as a predictor of the success of infertility treatment. Many factors determine ovarian reserve including genetic endowment, fetal environment, external environment (smoking, disease states), and iatrogenic interventions such as surgery, and medications (Tom et al, 2010). Oocyte related decline in ovarian function is referred to as decreased ovarian reserve.

Studies have shown that surgical procedures for benign conditions such as a hysterectomy, ovarian cystectomy, and uterine artery embolization can affect ovarian reserve (Jacob et al, 2016). The PROOF trial showed that women who have hysterectomies have menopause approximately 1.8 years earlier than women in control groups (Moorman et al, 2011). The EMMY trial showed that uterine artery embolization is associated with a $16 \%$ decrease in ovarian reserve (Hehankamp et al, 2007). Other studies have shown that embolization causes premature ovarian failure in approximately $2 \%$ of patients (Goodwin et al, 1999). Similarly, studies have shown that laparoscopic cystectomy for endometriomas can cause a $45-50 \%$ decrease in ovarian reserve after 3 months (Chang et al, 2010)(Hwu et al, 2011). The purpose of this study was to determine changes in ovarian reserve after gynecologic surgery for benign conditions that spared ovarian function over different periods of time.

\section{METHODS}

This was a single-centre prospective study conducted at London Health Sciences Centre, in London, Ontario, Canada. The study was approved by the Office of Research Ethics at Western University, London, Ontario, Canada. All patients involved had signed an informed consent prior to participating in the study.

The follow inclusion criteria were used to recruit patients 
1. Premenopausal women between the ages of 18 and 45 years

2. Surgery done for benign conditions only

3. Not pregnant

4. At least one ovary spared during the surgery

Patients were recruited if they underwent any of the following procedures

1. Abdominal Hysterectomy

2. Vaginal Hysterectomy

3. Ovarian Cystectomy

4. Unilateral Oophorectomy

5. Uterine Artery Embolization

Patients had blood drawn for anti-mullerian hormone $(\mathrm{AMH})$ prior to surgery and were asked to return to clinic for AMH levels for the follow points in time post-operatively: 3-6 months, 6-9 months, 9-12 months, and at one year following their surgery. AMH levels from these patients were then sent to a commercial lab test center for measurement. Samples were sent in bulk after they were collected. The samples were first separated using a centrifuge and only the supernatant was stored at -20 degrees Celsius in a freezer to prevent sample degradation. The sample collections were done between 2013 and 2015 .

The AMH results were then compared between preoperative and post operative levels to identify percentage changes over time. A proprietary spreadsheet software (Microsoft Excel 2016®) was used to create a line of best fit to assess trends for AMH levels.

\section{Results}

In total, 13 patients met the inclusion criteria and returned for post-operative AMH blood work. There were 3 patients who had ovarian cystectomies, 6 patients who had hysterectomies of any type, 2 patients who had unilateral oophorectomies, and 2 patients who had uterine artery embolizations.

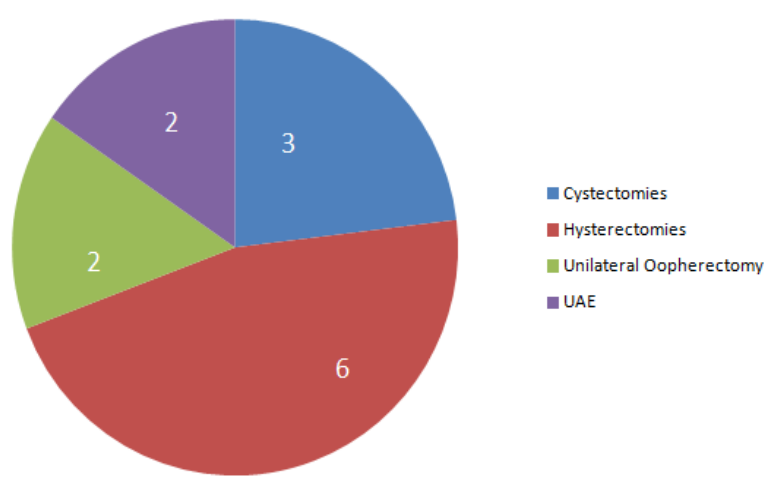

Figure1: Patient distribution based on type of surgery

\subsection{Hysterectomy}

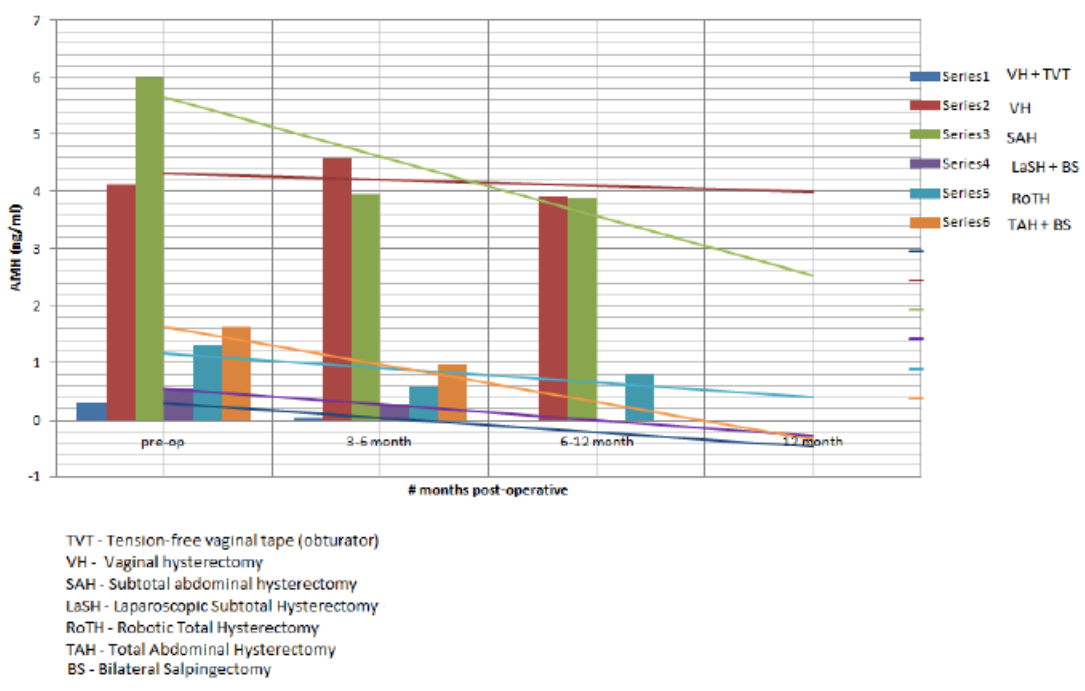

Figure 2: AMH results after hysterectomy 
The different types of hysterectomies included 2 vaginal hysterectomies, 2 open abdominal hysterectomies, and 2 minimally invasive hysterectomies (laparoscopic and robotic) Figure 2. A line of best fit, showed that all types of hysterectomies resulted in an eventual decrease in AMH levels (whether at the 3-6 month mark, or the 6-12 month mark). The only exception to this finding was that there was a transient increase in AMH levels at the 3-6 month mark after vaginal hysterectomy for one patient (Series 2). However, at the 6-12 month mark, AMH levels for this patient dropped to below the pre-operative level.

Table1.AMH results after hysterectomy

\begin{tabular}{|c|c|c|c|c|c|}
\hline Patient/Hysterectomy & Age & Co-morbidity & $\begin{array}{l}\text { Pre-op } \\
\text { AMH } \\
(\mathbf{n g} / \mathbf{m l})\end{array}$ & $\begin{array}{l}\text { Post-op 3-6 } \\
\text { month AMH } \\
\text { (ng/ml) }\end{array}$ & $\begin{array}{l}\text { Post-op 6-12 } \\
\text { month AMH } \\
\text { (ng/ml) }\end{array}$ \\
\hline 1/vaginal hysterectomy & 39 & smoker & 0.294 & 0.042 & N/A \\
\hline 2/vaginal hysterectomy & 34 & $\begin{array}{l}\text { smoker for } 5 \text { years; } \\
\text { previously had fibroid } \\
\text { resection and } \\
\text { endometrial ablation }\end{array}$ & 4.12 & 4.6 & 3.91 \\
\hline $\begin{array}{l}\text { 3/subtotal abdominal } \\
\text { hysterectomy }\end{array}$ & 35 & $\begin{array}{l}\text { Large fibroid uterus - } \\
20 \mathrm{~cm}\end{array}$ & 5.99 & 3.96 & 3.9 \\
\hline $\begin{array}{l}\text { 4/laparoscopic subtotal } \\
\text { hysterectomy + bilateral } \\
\text { salpingectomy }\end{array}$ & 45 & $\begin{array}{l}\text { Previous gastric bypass- } \\
\text { lost } 100 \mathrm{lbs} / \text { menorrhagia }\end{array}$ & 0.549 & 0.277 & N/A \\
\hline 5/robotic totalhysterectomy & 42 & healthy (menorrhagia) & 1.31 & 0.604 & 0.8 \\
\hline $\begin{array}{l}\text { 6/total abdominal } \\
\text { hysterectomy + bilateral } \\
\text { salpingectomy }\end{array}$ & 44 & healthy (fibroid uterus) & 1.63 & 0.973 & N/A \\
\hline
\end{tabular}

\subsection{Ovarian Surgery}

For the purpose of assessing the effect of ovarian manipulation on AMH levels, all patients who had any ovarian surgery (cystectomy or oophorectomy) were analysed together. AMH levels for patients with salpingooophorectomies had decreased over time (Patient 3 and 5) at the 6-12 month interval. However, of the 3 patients with ovarian cystectomies, only one patient showed a decrease in AMH levels (Patient 4) at the 3-6 month interval. The other 2 patients with ovarian cystectomies (Patients 1 and 2) had an overall increase in AMH levels at the 3-6 month interval.

Table2. AMH results after ovarian surgery

\begin{tabular}{|l|l|l|l|l|l|}
\hline \multicolumn{1}{|c|}{ Patient/surgery } & \multicolumn{1}{|c|}{ Age } & \multicolumn{1}{|c|}{ Co-morbidity } & $\begin{array}{c}\text { Pre-op } \\
\text { AMH } \\
\text { (ng/ml) }\end{array}$ & $\begin{array}{c}\text { Post-op 3-6 } \\
\text { month } \\
\text { AMH } \\
\text { (ng/ml) }\end{array}$ & $\begin{array}{c}\text { Post-op 6- } \\
\mathbf{1 2} \text { month } \\
\text { AMH } \\
\text { (ng/ml) }\end{array}$ \\
\hline $\begin{array}{l}\text { 1/laser laparoscopy + left } \\
\text { oophoro-cystectomy }\end{array}$ & Healthy/Mature Cystic Teratoma & 4.06 & 5.36 & N/A \\
\hline $\begin{array}{l}\text { 2/laser laparoscopy }+ \\
\text { excision of endometrioma }\end{array}$ & 31 & Healthy/Endometrioma & 4.22 & 6.15 & N/A \\
\hline $\begin{array}{l}\text { 3/laser laparoscopy + left } \\
\text { salpingo-oophorectomy }+ \\
\text { right ovarian lysis }\end{array}$ & Healthy/Endometrioma & 5.18 & N/A & 1.37 \\
\hline $\begin{array}{l}\text { 4/laser laparoscopy } \\
\text { bilateral ovarian lysis }+ \\
\text { left ovarian cystectomy }\end{array}$ & Healthy/Endometrioma & 4.36 & 2.13 & N/A \\
\hline $\begin{array}{l}\text { 5/abdominal right } \\
\text { salpingo-oophorectomy }\end{array}$ & 34 & Healthy/Endometrioma & 8.54 & 4.23 & 2.07 \\
\hline
\end{tabular}




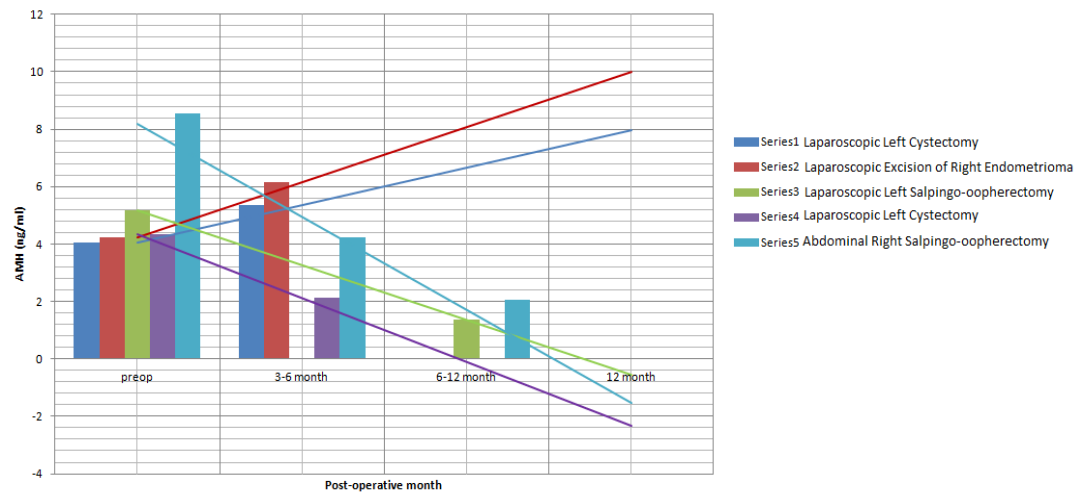

Figure 3: AMH results after ovarian surgery

\subsection{Uterine Artery Embolization}

Uterine artery embolization was assessed for two patients. The overall trend for one of the patients (Series 1) was that there was a decrease in AMH levels at the 12 month mark, whereas for the other -patient (Series 2) there was a significant increase in AMH levels at the 12 month mark.

Table3. AMH results after uterine artery embolization

\begin{tabular}{|l|l|l|l|l|l|l|}
\hline Patient & Age & Co-morbidity & $\begin{array}{l}\text { Pre-op } \\
\text { AMH } \\
\text { (ng/ml) }\end{array}$ & $\begin{array}{l}\text { Post-op 3-6 } \\
\text { month AMH } \\
(\mathbf{n g} / \mathbf{m l})\end{array}$ & $\begin{array}{l}\text { Post-op 6-12 } \\
\text { month AMH } \\
(\mathbf{n g} / \mathbf{m l})\end{array}$ & $\begin{array}{l}\text { Post-op 12 } \\
\text { months AMH } \\
(\mathbf{n g} / \mathbf{m l})\end{array}$ \\
\hline 1 & 41 & Large fibroid -12cm & 1.42 & 0.957 & 0.459 & 0.604 \\
\hline 2 & 39 & $\begin{array}{l}\text { Smoker; late onset congenital } \\
\text { adrenal insufficiency }\end{array}$ & 0.706 & 0.665 & 1.17 & 1.86 \\
\hline
\end{tabular}

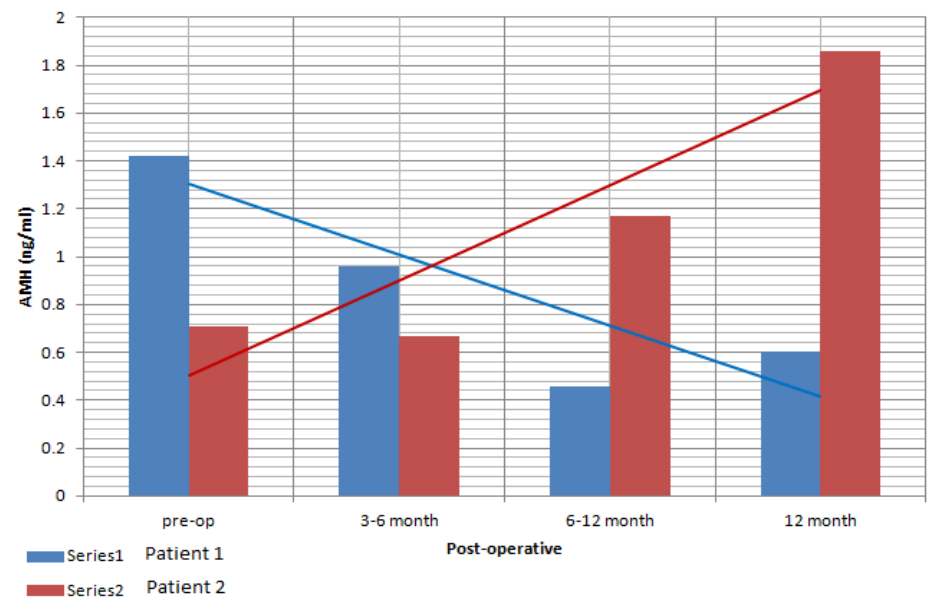

Figure 4: $A M H$ results after uterine artery embolization

\section{DISCUSSION}

The results of the study can be categorized based on the type of surgery performed. Following hysterectomy, all patients had a loss in ovarian reserve over time regardless of method of hysterectomy (abdominal versus laparoscopic versus vaginal). These results seem to suggest that ovarian blood supply is compromised regardless of the method of hysterectomy. This is consistent with the studies showing that hysterectomies cause earlier menopause by approximately 1.8 years (Moorman et al, 2011). However, it is interesting to note that a change in ovarian reserve was seen even in the least invasive methods of hysterectomy (that is, vaginal hysterectomy).
Not surprisingly, for patients who had a unilateral oophorectomy, AMH levels decreased over time. These results may be expected given that these patients lost half of their ovarian reserve. For patients who had cystectomies, three out of five patients had a significant decline in ovarian reserve. However, ovarian reserve increased after the remaining two patients had surgery. This result is contrary to previously done studies suggesting that cystectomies impair ovarian reserve. This could be because laparoscopy surgery using laser energy removed pathology (endometriosis) that allowed for improved recruitment of follicles, and thereby an increase in AMH levels. For the patients who had a decline in ovarian reserve after cystectomy, their results were in keeping 
with what is typically seen after surgery for endometriosis.

This study had only two patients who underwent uterine artery embolization. One patient aged 41 years started off with a high ovarian reserve; at the twelve month follow up, she had a significant decrease in ovarian reserve over time. The second patient, aged 39 years, started off with a low ovarian reserve and had significantly improved AMH levels at the twelve month post-embolization. The patient who had the increase in AMH might have benefited from shunting of blood away from the ischemic fibroid to the ovaries. The other patients' results are in keeping with what is seen in literature (2\% rate of premature ovarian failure after embolization) (Hehenkamp et al, 2006).

The strength of this study is that it is a long-term assessment of ovarian function done in a prospective manner. In addition, it is one of the few studies (if not the only study) that has taken pre-operative AMH levels in patients to serve as each patient's own control. However, it has significant limitations. Our primary drawback was the small number of patients in this study. Given that patients had to return to clinic on their own volition, many of them were lost to follow-up after surgery. Only 13 patients had at least one follow up blood test. Some of the results of the study are controversial, such as the rise in $\mathrm{AMH}$ after cystectomy and after uterine artery embolization. However, one study showed that there can be recovery in ovarian reserve after cystectomy when compared between 1-month post-operative and 1-year post-operative day (Sugita et al, 2013).

Change in AMH after uterine artery embolization should be prospectively studied for long term periods (at least twelve months) with a large sample in order to further explore the trend of an increase in AMH level. Current evidence for long term studies looking at uterine artery embolization and anti-mullerian hormone levels are mostly limited to retrospective studies and often without pre-operative AMH levels to serve as the patient's own control (Arthur, Kachura, Liu, Chan, \& Shapiro, 2014). In addition, future studies should look at the role of laser laparoscopy in sparing ovarian reserve after cystectomies for severe endometriosis.

\section{REFERENCES}

[1] Arthur, R., Kachura, J., Liu, G., Chan, C., \& Shapiro, H. (2014). Laparoscopic myomectomy versus uterine artery embolization: long term impact on markers of ovarian reserve. Journal of Obstetrics and Gynecology, 36, 240-247.

[2] Chang, H.J., Han, S.H., Lee, J.R., Jee, B.C., Lee, B.I., Suh, C.S., \& Kim, S.H. (2010). Impact of laparoscopic cystectomy on ovarian reserve: serial changes of anti-Mullerian hormone levels. Fertility \& Sterility, 94, 343-349.

[3] Goodwin, S.C., McLucas, B., Lee, M., Chen, G., Perrella, R., Vedantham, S., ... DeLeon, M. (1999). Uterine artery embolization for the treatment of uterine leiomyomata midterm results. Journal of Vascular and Interventional Radiology, 10, 1159-1165.

[4] Jacob, G.P., Oraif, A., Power, S. (2016). When helping hurts: the effect of surgical interventions on ovarian reserve. Human Fertility, 16, 3-8.

[5] Hehenkamp, W.J., Volkers, N.A., Broekmans, F.J., de Jong, F.H., Themmen, A.P., Birnie, E., ... Ankum, W.M. (2007). Loss of ovarian reserve after uterine artery embolization: a randomized comparison with hysterectomy. Human Reproduction, 22, 1996-2005.

[6] Hwu, Y., Wu, F.S., Li, S., Sun, F., Lin, M., \& Lee, R.K. (2011). The impact of endometrioma and laparoscopic cystectomy on serum AMH levels. Reproductive Biology and Endocrinology, 9, 80-88.

[7] Moorman, P.G., Myers, E.R., Schildkraut, J.M., Iversen, E.S., Wang, F., \& Warren, N. (2011). Effect of hysterectomy with ovarian preservation on ovarian function. Obstetrics Gynecology, 118, 1271-1279.

[8] Sugita, A., Iwase, A., Goto, M., Nakahara, T., Nakamura, T., Kondo, ... Kikkawa, F. (2013). One-year follow-up of serum antimullerian hormone levels in patients with cystectomy: are different sequential changes due to different mechanisms causing damage to the ovarian reserve? Fertility \& Sterility, 100, 516-522.

[9] Tom, S.E., Cooper, R., Kuh, D., Guralnik, J.M., Hardy, R., \& Power, C. (2010). Fetal environment and early age in natural menopause. Human Reproduction, 25, 791-798.

Citation: Jacob GP, Mc Murphy L, Vilos GA \& Power SP. The Effect of Benign Gynecologic Procedures on Ovarian Reserve: A Prospective Study. ARC Journal of Surgery.2017; 3(4): 5-9. doi: dx.doi.org/ 10.20431/2455-572X. 0304002.

Copyright: (C) 2017 Authors. This is an open-access article distributed under the terms of the Creative Commons Attribution License, which permits unrestricted use, distribution, and reproduction in any medium, provided the original author and source are credited. 